\title{
Inclusive Education in Bangladesh: Digging Deeper into Educational Prospects of Children with Disabilities in Bangladesh
}

\author{
Bushra Zulfiqar \\ Mohammed Kamal Hossain \\ Md. Shahinujjaman \\ Md. Najmul Hossain \\ Education Team, Save the Children, Bangladesh \\ HOPE, Education Sector, Save the Children, Bangladesh
}

\begin{abstract}
This paper explores multiple dimensions of inclusive education in Bangladesh's targeted schools. It compares the educational performance of children with disabilities to children without disabilities analysing their participation, retention and school completion rates. Through quantitative and qualitative analysis, it tries to explore the existing inclusive education practices at school level for quality and learning. The study uses community resource mapping, open-ended interviews, field observations, a quality assessment framework and literature review as the main research tools. The study found that at the primary level while significant number of children with disabilities enrol, their participation gradually decreases in the upper classes. In the targeted schools, enrolment of children with disabilities was at $35 \%$ in grade 1 , which reduced to $31.5 \%$ in grade 2 , further to $25 \%$ in grade 3 and to as low as $8.5 \%$ in grade 4 , demonstrating a consistent decline in participation rates $(\sigma \pm 11.7)$. Thus it became clear that significant number of children with disabilities were unsuccessful to get promoted to the next grade or got dropped out every year from the schools. The study findings also suggest that despite the drop outs, teachers in the targeted schools found the enthusiasm and responsiveness of children with disabilities highly positive.
\end{abstract}

Keywords: inclusive education, children with disabilities, educational performance, quality education, learning environment

\section{Introduction}

Since Salamanca Declaration, globally there has been a major shift from segregated modes of education towards inclusion. The values of inclusive education would ensure welcoming environment in schools, free from the effects of negative forms of discrimination based on gender, culture, ethnicity, disability, religion or socio-economic backgrounds have gained growing recognition (UNESCO, 1994). However, it is still a long way to go before educationists worldwide can claim to have embedded inclusiveness systematically and consistently across the vast spectrum of education. It has been found that teachers in particular feel less confident and motivated to include children with disabilities in their teaching and pedagogical delivery (Forlin, C. et al., 2009). The importance and effectiveness of child centred, customized teaching-learning approaches are yet to be fully conceived and materialized.

In Bangladesh children with disabilities have traditionally been among the most marginalized group of children. The impact on their educational development is often severe and vastly hampers their growth potential. A recent study found that, of an estimated 1.6 million children with disabilities of primary school age, only $4 \%$ have access to education. In areas where there were disability-related interventions exist, $18 \%$ had this access. Of this group $48 \%$ were enrolled in formal education, $23 \%$ in privately run integrated schools, $15 \%$ in special education, $5 \%$ in inclusive education programs and $9 \%$ in various other types of education. It also found that the proportion of students with disabilities in school decreased with age, falling from $44 \%$ among children aged 6 to 10 to just $15 \%$ among adolescents aged 16 to 18 years, indicating high dropout rates (Directorate of Primary Education DPE, 2002).

Currently the number of children with special needs enrolled in DPE managed schools grew faster than the Government of Bangladesh sector program Primary Education Development Program II (PEDP II) targets for all types and in particular for 
children with physical disabilities and eyesight problems. There was a striking $50 \%$ increase in the numbers of special needs children between 2005 and 2011. The enrolment trend gradually declined from 2012 and stands at 76,522 in 2014. The reason might be the teachers were not properly trained in recognizing the children with special needs before 2012 (DPE, 2015). However, it is not clear to what extent the trend indicated growing enrolment or simply better identification of students with disabilities. There is a need to continue to enhance regular data collection methods to ensure children with disabilities are counted in order to argue for appropriate resource allocation for inclusive education. Despite significant progress in access to primary education, 4 million school going age children including children with disabilities are still out of school in Bangladesh (BBS, 2014). This indicates that the ensuring Right to Education to all children is still a multi-fold challenge in the education system of Bangladesh.

Considering this context, education team of Save the Children in Bangladesh felt the need for an explorative research to assess the present educational status of children with disabilities in the targeted areas of an inclusive education project: Holistic approach towards Promotion of Inclusive Education(HOPE). It is being implementing in Belkuchi, Karimganj and Savar Upazilas of Sirajganj, Kishoreganj and Dhaka districts of Bangladesh respectively. The project is working with 45 government primary schools (15 per Upazila) as well as 6 Unions in these areas. The key objective of this project is to reduce the discrimination against the children with disabilities in the education system and improve quality of education for all children through inclusive education approaches. The research question was twofold:

what is the performance of children with disabilities in targeted schools in comparison to other children (Peers), particularly in terms of retention, participation, and completion, and

what are the existing inclusive education approaches and practices in the targeted school in terms of learning environment, materials and methodologies?

\section{The Context of Inclusive Education}

As per the Sustainable Development Goal (SDG) 4 the new target for all developing countries is to develop an equitable, inclusive and quality education system for all children by the year 2030 (UNDP, 2015). All countries throughout the world including Bangladesh are attempting to address the inequalities and barriers in access and quality of education through inclusive education reforms. Different international policy reform initiatives such as Education For All (EFA) 1990, the Salamanca Declaration (UNESCO, 1994), Millennium Development Goals (MDGs) (UN, 2008); the UN Convention on the Rights of Persons with Disabilities have influenced different national policies in Bangladesh, for instance, the National Plan of Action Phase II (NPA II) 2003-2015 (MoPME, 2003), National Education Policy 2010 (MoE, 2010) and interventions that include the Second Primary Education Development Program (PEDP 2), PEDP 3 in the primary education sector and the Teaching Quality Improvement (TQI-SEP) in the secondary education sector. Specifically, the National Education Policy 2010 (MoE, 2010) has made systematic attempts to integrate children with disabilities in the mainstream schools and conduct training for at least one teacher from each school on how to teach children with disabilities. These initiatives are some of the milestones of the Government of Bangladesh's intention to enact the principles of improving learning for all students.

In an inclusive education setting, it is very important to cherish learners' diversity recognizing their unique educational needs. It focuses both on the quantity and quality of the education system. Conceptually, inclusive education means improving whole school environment to ensure presence, participation and achievement of all children with an aim of achieving quality education for all learners (Ainscow, 2005). Many educationalists (e.g. Ainscow, 2005) opined that the broader objective of inclusive education is to achieve equity and social justice for all citizens in every aspect of life. Ainscow (2005) defines inclusive education as, "The process of addressing barriers to the presence, participation and achievement of pupils in local neighbourhood schools". The guideline prepared by the UNESCO (2009) based on the International Conference on Education (ICE) 2008 described Inclusive Education as a"process aimed to offering quality education for all while respecting diversity and the different needs and abilities, characteristics and learning expectations of the students and communities, eliminating all forms of discrimination" (p. 18).

Hence, it is clear from reviewing different definitions of inclusive education that the values of inclusive education are to include all children into education in a meaningful way. It is also important to note that inclusion does not mean just enrolling children into schools; rather it demands full and equal participation as well as completion of a quality education cycle by all children. Long term policy reform initiatives need to be taken into account to understand how the policies promoted the 
concept of inclusive education over the years. Based on the globally accepted concept of inclusive education, the Government of Bangladesh has developed the functional definition of inclusive education through the PEDP 3 documents which is as follows:

"Inclusive Education is an approach to improve the education system by limiting and removing barriers to learning and acknowledging individual children's needs and potential. The goal of this approach is to make a significant impact on the educational opportunities of those: who attend school but who for different reasons do not achieve adequately and those who are not attending school but who could attend if families, communities, schools and education systems were more responsive to their requirements" (Ahuja \& Ibrahim, 2006, p. 6).

Save the Children has a strong policy position in this regard and defines inclusive education as "one dimension of a rights based quality education which emphasizes equity in access and participation, and responds positively to the individual learning needs and competencies of all children". Together with development community and other stakeholders, it actively works to ensure that every child, irrespective of gender, language, ability, religion, nationality or other characteristics, is supported to meaningfully participate and learn alongside his/her peers, and develop to his/her full potential' (SC, 2014). The success of an inclusive education intervention largely depends on teachers because they are to play the most crucial role in classroom practice (Jerlinder et al, 2010). A number of studies suggest that teachers also develop negative attitudes towards students with children with disabilities and they are less likely to accept any changes in their pedagogical practices (Barnyak \& Paquette, 2010); Malak, 2013).

Shedding light on the broader exclusion context in Bangladesh, a major education player Campaign for Advancement of Mass \& Popular Education (CAMPE)in 2011 reported that large percentage of children with disabilities are still out of mainstream education. The rate of enrolment among these children is very low to begin with and further compromised by lack of adaptive ability within the school environment, no or low scopes of personal assistance, absence of accessible transportation, inaccessible infrastructure and environment, negative attitude of the family, teachers and community. Most of the children with disabilities initially enrolled do not complete their primary education due to reasons like lack of public transportation, inaccessible transportation, absence of trained teachers, absence of accessible disability friendly toilet in schools, inaccessible school environment, negative attitude of parents, teachers and bullying by peer children and no or low implication of the existing policy related to education of children with disabilities. Research also show that specialized training for teaching students with learning disabilities can help educators and teachers feel more capable and become effective while teaching students with disabilities (Kosko \& Wilkins, 2009). However, Munir and Islam (2005) reviewed the Bangladesh's primary level pre-service teacher training curriculum and reported that the curriculum lacks inclusive education related materials. Additionally, another evaluative study on the state of inclusive education in Bangladesh conducted by Ahuja and Ibrahim in 2006, reported that the pre-service teacher training program was not supportive enough for the primary school teachers to be confident and competent for inclusive classrooms.

For children with disabilities some special learning materials are required. Special needs learning materials include speech and language development, social and emotional skills, motor skills, sensory awareness, tactile awareness, visual discrimination, core skills and professional resources. In the mainstream schools these resources are not available to facilitate special need children and it makes the any learning very difficult and challenging (Kawser, U., Ahmed, M., Ahmed, M. 2016).

There have been few studies looking at the academic achievement of regular education students in an inclusive classroom setting with special education students. The overwhelming majority of the research is qualitative in nature and focused on successful instructional strategies for inclusive settings. Robert Scott Spence (2010) examined the effects of inclusion on the academic achievement of regular students. The academic performance of regular education students placed in an inclusive setting with children with disabilities was compared to the academic performance of regular education students not placed in an inclusive setting. No significant difference was found in the performance. Similarly Sermier Dessemontet R. Bless G. (2013) examined the impact of children including children with intellectual disability (ID) in general education classrooms with support on the academic achievement of their low-, average-, and high-achieving peers without disability and found that there are no significant differences in the progress of the low- average, or high-achieving pupils from classrooms with or without inclusion. In terms of educational achievement in inclusive settings, there is no significance difference in the academic performance of regular education students placed in an inclusive setting with children with disabilities compare to students who are in non-inclusive settings. 


\section{Materials and Methods}

Both qualitative and quantitative data were collected, considered and analysed to explore the present scenario of educational progress of children with disabilities in Government Primary Schools (GPS) of 3 Upazila (Savar, Belkuchi and Karimganj) of 3 districts (Dhaka, Sirajganj and Kishoreganj). Community Resource Mapping (CRM), Parents Opinion Survey (POS), Semi-structured interview, Focus Group Discussions (FGD), literature review, and Quality Learning Environment (QLE) assessment tool have been conducted to collect data from different stakeholders. This study has been accompanied in the Save the Children HOPE project areas Belkuchi, Savar and Karimganj Upazila. Total 45 schools were selected, 15 GPS from each Upazila. In line with the aims of the study, 45 schools and their catchment areas were the population of this study where CRM have been drawn initially. As per CRM data a total of 400 parent's opinion survey was conducted to explore the present situation of children's educational rights.

To explore quality learning environment of schools a Quality Learning Environment (QLE) assessment has been done in 45 GPS. In basic education of the QLE, four guiding principles are generated that reflects the conditions under which children are most likely to thrive and learn. The guiding principles for QLE are:

Guiding Principle One: Save the Children - supported education programs meet the emotional and psychological needs of children.

Guiding Principle Two: Save the Children-supported programs are protective of children's physical wellbeing.

Guiding Principle Three: Save the Children - supported programs encourage and support active engagement for learners, child centred teaching, and improved learning outcomes of all the learners.

Guiding Principle Four: In Save the Children - supported education programs, parents and local communities are actively involved in planning, decision-making and actions to improve education.

In QLE Assessment tool according to the guideline there are different indicators which are measured by 4 rating scales. The following definitions have been followed for scoring:

\author{
Score \\ $1=$ Indicator is not at all achieved. \\ $2=$ Indicator is partially achieved \\ $3=$ Indicator is achieved \\ $4=$ Indicator is exceeded
}

Not Applicable (NA)

\begin{abstract}
Description/Meaning
There is no evidence that any effort have been made to achieve the monitoring indicator

Some efforts to achieve the monitoring indicator are observed, although they are not enough to achieve the indicator. Some additional work is required to ensure the indicator to be achieved

There is consistent evidence that the monitoring indicator has successfully reached the learning environment

There is direct and consistent evidence that level 3 has been achieved and that the indicator has exceeded education project/program level expectation or objectives. There is evidence that a variety of method is used to go beyond the minimum expectation set by the education project/program and ensures an exceptionally high/excellent level of quality during implementation

NA used if the project or program activities do not specifically target the activities described by an item. For example, if the project does not deal with program refurbishment or construction, the data collector can score NA to items that do not deal with a program or learning site's physical environment.
\end{abstract}

However, to compare the learning outcomes of children with and without disabilities annual performance data has been collected from 15 schools ( 5 from each Upazila). In total 191 children were selected for data collection who are currently studying in grade one to four, learner performance measuring tools have been used to collect annual performance data of respective children. There were six schools (two schools from each Upazila) selected purposively to conduct FGDs and semi-structured interviews for triangulation of data. FGD was conducted with parents and students and semi-structured interviews were conducted with Upazila Education Officers, Assistant Upazila Education Officers, Head Teachers, Assistant 
Teachers, Union Parishad Chairman/ members, Partner Organization Officials and School Management Committees (SMCs).

\section{Results and Discussion}

This section includes the data analysis and findings from quality learning environment assessment, learner's performance measurement, community resource mapping, parent's opinion survey and FDGs. Before presenting details findings a summary of demographic information is presented:

\section{Demographic Information}

The demographic information is derived from the Parents Opinion Survey data followed by Community Resource Mapping (CRM) findings. From three Upazilas, a total of 400 out of school children including children with disabilities were found through community resource mapping. Parent's opinion Survey was conducted with the parents of these $400 \mathrm{children}$. It is also analysed that 278 children are out of school and among them 112 are children with disabilities. On the other hand, in total 156 are dropped out from the schools which includes both children with and without disabilities. Most of the children are aged between 9 to 14 years and $63.5 \%$ are male. Among the respondents, $41.50 \%$ are aged between 26 to 35 years. Moreover, $64 \%$ of them are female, $96.25 \%$ are Muslim, $40.75 \%$ are illiterate, $31.75 \%$ have level of education below grade $V$ and $94 \%$ have level of education below Grade X, $54 \%$ have family member between 5 to $7,71 \%$ families monthly average income below 5000 Taka (below USD 2 per day).

\section{Learning outcome of children with disabilities in comparison with other children (Peers)}

\section{Retention}

Study revealed that, though it has been said by the school authority and education officials that almost $100 \%$ child are enrolled in that areas but still a big number of children are not in school. The national enrolment rate has the same success story of having $97.94 \%$ children enrolled in the education system. However, the completion rate is $80 \%$, leaving $20 \%$ children out of school by grade five (DPE, 2012). It has been found that, among the children with disabilities $(n=234)$ only $52 \%(n=122)$ children are now going to schools and almost $48 \%(n=112)$ children are being out of school (figure 1$)$. Among the identified household, 234 children with disabilities have been observed considering their visible disability or impairment.

\section{Enrolment scenario of children with disabilities}

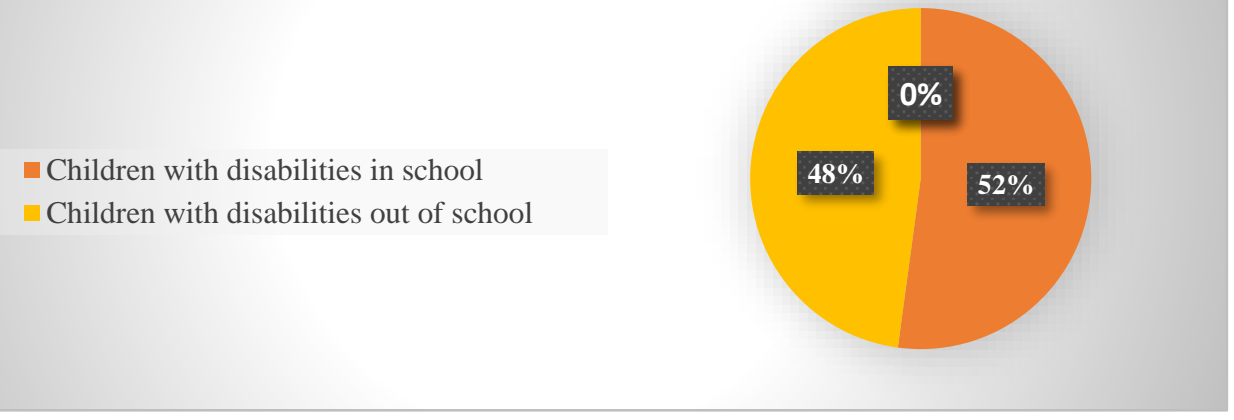

Figure 1: Enrolment and out of school scenario of children with disabilities.

\section{Participation}

the Assistant Teachers of Selected Schools Argued that, "We Try to Engage Students as Much as Possible in the Lessons. However, It Was Not Always Possible to Make 100\% Participation in the Class as the Number of Students Are Huge". Some of the Teachers Also Mentioned that They Try to Ask Individual Questions, Give Class Work and Evaluate the Note Book, Make Groups and Ask Questions to the Group or Group Leader to Present Sometimes Based on the Topic Etc. in Classroom Children Also Participate in Classroom Management and Co-Curricular Activities. While Giving the Information 
About Students' Participation in School Development and Student Voice, the Assistant Head Teacher Uttered that, "Students Seems Involved in Organising the Cultural Program and Also in Class Leadership".

in Classroom Observation, It Was Found that Most of the Students Were Participating in the Lessons and Were Actively Engaged as Well as Teachers Were Found Very Positive and Following An Interactive Teaching Methodology Through Group Work. Assistant Teachers Mentioned that, Group Work Activities Engage All the Students Even Those Who Feel Shy to Talk and Participate Visibly. Besides Group Work, Teachers Also Do Lecture Method and Use Question-Answer Method to Assess the Students. Though They Believed that It is Not Possible to Measure All the Students Learning Outcome with Only Question-Answer Method, Still According to Them, Big Classroom Size Indirectly Forces Them to Do so. Based on the QLE Data (Figure 2) It Has Been Found that, a Number of Schools of Karimganj and Savar Upazilas, Except for Belkuchi Achieved the Indicator on 'Learners' Participation During Development and Implementation of Teaching and Learning Activities". It Was Also Found that Few Schools from Both Savar and Karimganj Upazila Achieved the Indicator of "Participation During Teaching and Learning Activities for Children at Risk of Marginalization", Whereas Belkuchi Upazila Could Not Achieve this Indicator at All.

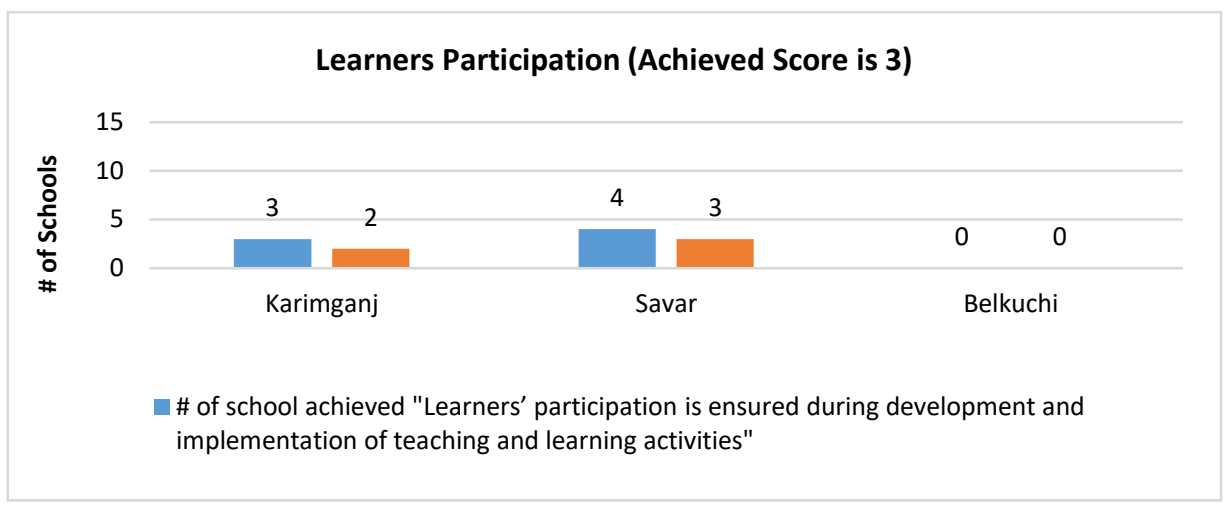

Figure 2: QLE Standard Indicator showing learners participation.

In Social and Cultural Activities, Though Children with Disabilities Who Are in School Get the Opportunities to Participate, but Their Level and Quality of Participation Remains Low. Data Revealed that, $61.44 \%$ Children with Disabilities Who Go to School, Participate to Some Extent in Sports and Cultural Activities Whereas Only 18.69\% Out of School Children with Disabilities Participated in the Sports and Cultural Activities (Table 1).

\section{Table 1: Participation of sports and cultural activity}

\begin{tabular}{|l|l|l|}
\hline Participating in sports and cultural activity \\
\hline Children type & Yes/No & Percentage \\
\hline Child with disability in school & Yes & $61.44 \%$ \\
\cline { 2 - 3 } & No & $38.55 \%$ \\
\hline Child with disability out of school & Yes & $18.69 \%$ \\
\cline { 2 - 3 } & No & $81.30 \%$ \\
\hline \multirow{2}{*}{ Out of school children } & Yes & $34.45 \%$ \\
\cline { 2 - 3 } & No & $65.54 \%$ \\
\hline
\end{tabular}

Similarly, only $10.84 \%$ children with disabilities who are in school can participate in social club activity, whereas only $0.9 \%$ children with disabilities from out of school children can participate in social/ club activity (Table 2).

\section{Table 2: Participation of Social/club Activity}

\begin{tabular}{|l|l|l|}
\hline Participating in social/club activity & Yes/No & Percentage \\
\hline Child Type & \\
\hline
\end{tabular}




\begin{tabular}{|l|l|l|}
\hline Child with disability in school & Yes & $13.11 \%$ \\
\cline { 2 - 3 } & No & $86.89 \%$ \\
\hline Child with disability out of school & Yes & $1.7 \%$ \\
\cline { 2 - 3 } & No & $98.03 \%$ \\
\hline \multirow{2}{*}{ Out of school children } & Yes & $5.57 \%$ \\
\cline { 2 - 3 } & No & $94.42 \%$ \\
\hline
\end{tabular}

A school going child also said that, "Soikot (name of child with disability) do not participate in the game with us. I think he should participate, but I fear, if he gets hurt".

\section{Completion}

In total 40 Children with disabilities were enrolled in 15 GPS. Among them $42.5 \%$ were girls' which is significantly less than boys $(57.5 \%)$. It was also found that, among the enrolled children, $27.5 \%$ children had physical disability which is higher than others form of disability that are $22.5 \%$ children had speech impairment, $15.7 \%$ children had visual impairment, $7.5 \%$ had hearing impairment, $5 \%$ had psychosocial problems and rest $20 \%$ were in others categories.

In the school, it was observed that number of children with disabilities decreased gradually in the upper classes. Data showed that, total number of children with disabilities in the school were $35 \%$ in grade $1,31.5 \%$ in grade $2,25 \%$ in grade 3 and $8.5 \%$ in grade $4(\sigma \pm 11.7)$. So, it is clear that significant number of children with disabilities failed to be promoted next grade or dropped out every year from the schools (Figure 3). As per POS, $26 \%$ parents' shared the major reason for out of school was functional disability of the children, parent's unawareness, interested to enrol in Madrashas (Kaumi) and not accepted by the schools primarily. On the other hand, $19 \%$ parents thought that major reason of children dropped out is also similar and $8 \%$ parents addressed their economic problem as a major barriers of children drop out.

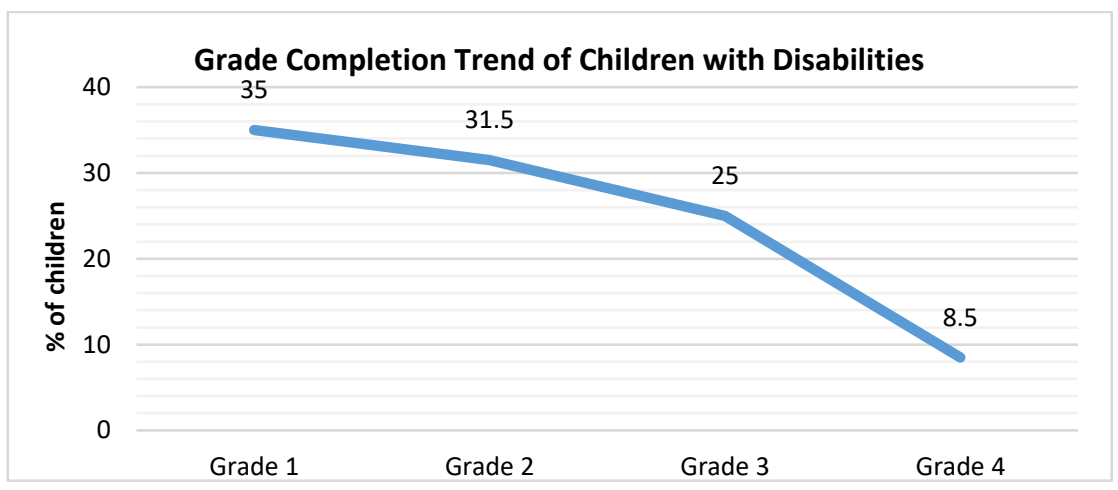

Figure-3: Grade Completion Trends of Children with disabilities.

In order to understand the performance of children with disabilities comparing to other students, grade wise performance and score in last year in Bangla, Math and English of grade 1 to 4 was analysed. It was found that performance of children without disabilities in these three subject is better than the performance of children with disabilities. Among three subjects, performance in English $(\sigma \pm 10.5)$ where $17.5 \%$ children with disabilities and $2.7 \%$ children without disabilities failed which is comparatively poor than Bangla $(\sigma \pm 7.4)$ where $15 \%$ children with disabilities and $4.6 \%$ children without disabilities failed and in Maths ( $\sigma \pm 6.5) 12.5 \%$ children with disabilities and 3.3\% children without disabilities failed. In overall result, $15 \%$ children with disabilities were failed where only $4.6 \%$ children without disabilities failed ( $\sigma \pm 7.4$ ) (Figure 4). It was also found that for boys (with disability) enrolment rate is higher than girls (with disability). But girl's performance is better than boys. In the last year school final exam, overall $21.7 \%$ boys failed which is three times higher than girls $(5.9 \%)(\sigma \pm 11.1)$. We have found similar trends in the subjects of Bangla, English and Math; girl's performance is better than boys. 


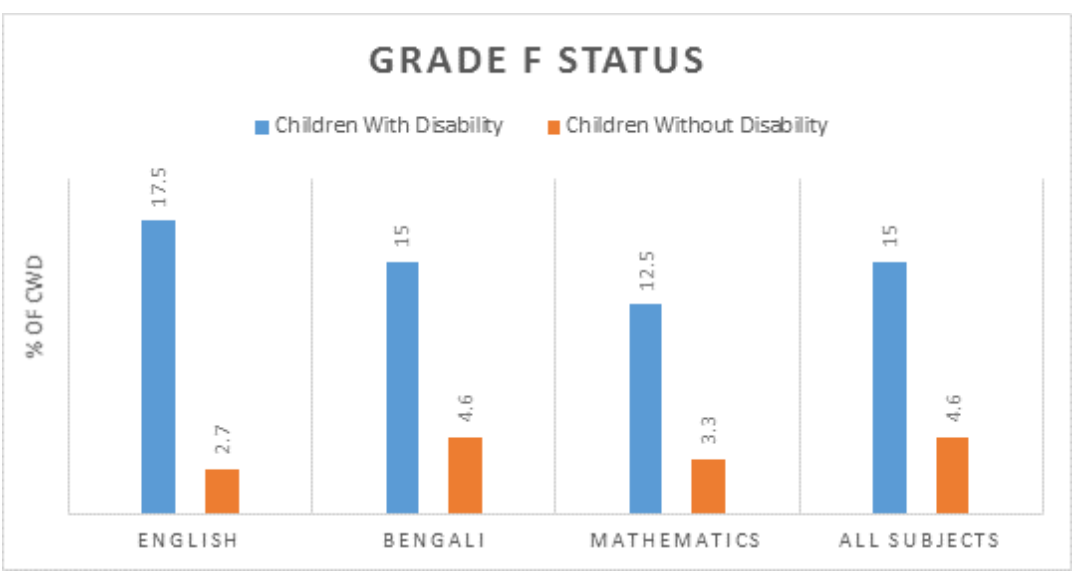

Figure 4: Grade wise failed status of children with and without disabilities.

Inclusive Education Approach

\section{Learning Environment}

Considering QLE standard and inclusive, it has been analysed that the obtained score of 4 guiding principles for 45 GPS is 1.94 and 1.74 respectively out of $4(\sigma \pm 0.15)$. So its reveals that out of selected target schools, not a single school has achieved all guiding principles together i.e score is 3 to 4 (Table 3 ).

Table 3: Quality Learning Environment in the Schools

\begin{tabular}{|l|l|l|}
\hline $\begin{array}{l}\text { QLE Guiding Principle } \\
\text { (Scoring: 3-4= Achieved, <3=Not Achieved) }\end{array}$ & $\begin{array}{l}\text { QLE Standard Score } \\
\text { (out of 4) }\end{array}$ & $\begin{array}{l}\text { QLE Inclusive Score } \\
\text { (out of 4) }\end{array}$ \\
\hline Meet the emotional and psychological needs of learners & 1.99 & 1.88 \\
\hline Protective of children's physical wellbeing & 2.10 & 1.82 \\
\hline $\begin{array}{l}\text { Encourage and support active engagement for learners, child cantered } \\
\text { teaching, and improved learning outcomes of all learners }\end{array}$ & 1.95 & 1.75 \\
\hline $\begin{array}{l}\text { Parents and local communities are actively involved in planning, decision- } \\
\text { making and action to improve education }\end{array}$ & 1.79 & 1.53 \\
\hline Average Result & 1.96 & 1.74 \\
\hline
\end{tabular}

QLE data also shows that few schools of Karimganj and Savar Upazila have achieved (obtained score 3) the "accessible learning space" component of QLE inclusive indicator, while Belkuchi could not achieve it at all. On the other hand, very few schools of Savar and Belkuchi Upazila achieved the indicator on "accessible learning environment in terms of hours, locations and fees including children with disabilities" but Karimganj could not achieve it (Figure 5). 


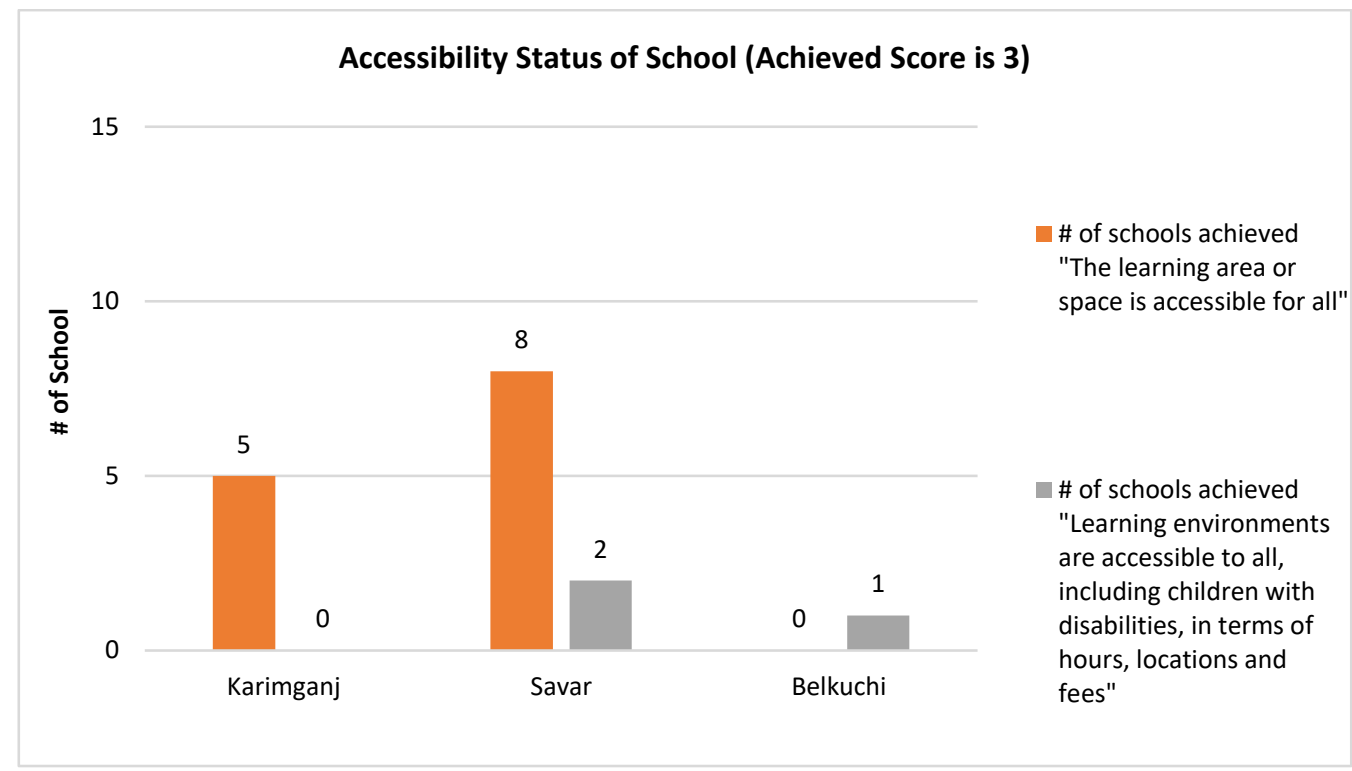

Figure 5: QLE Inclusive Indicator showing accessibility status of school.

Regarding QLE inclusive indicator, more number of schools (13) in Savar and Karimganj Upazila have achieved the indicator "Teachers are present in their classes" $(\mu=3)$ while Belkuchi Upazila having less $(\mu=2)$ than compared to that two Upazilas. However, in case of providing continuous support in relation with inclusive education to improve their practice in classroom, some schools of Savar, Belkuchi and Karimganj (only $27 \%$ out of 45 GPS) achieved the indicator. Moreover, about the indicator on "Teachers develop, follow and adapt lesson plans to the needs and abilities of learners in their classes in a systematic way" Belkuchi and Savar Upazila did not achieve the indicator $(\sigma \pm 0.7)$ at all whereas only one school of Karimganj Upazila achieved this indicator (Figure 6).

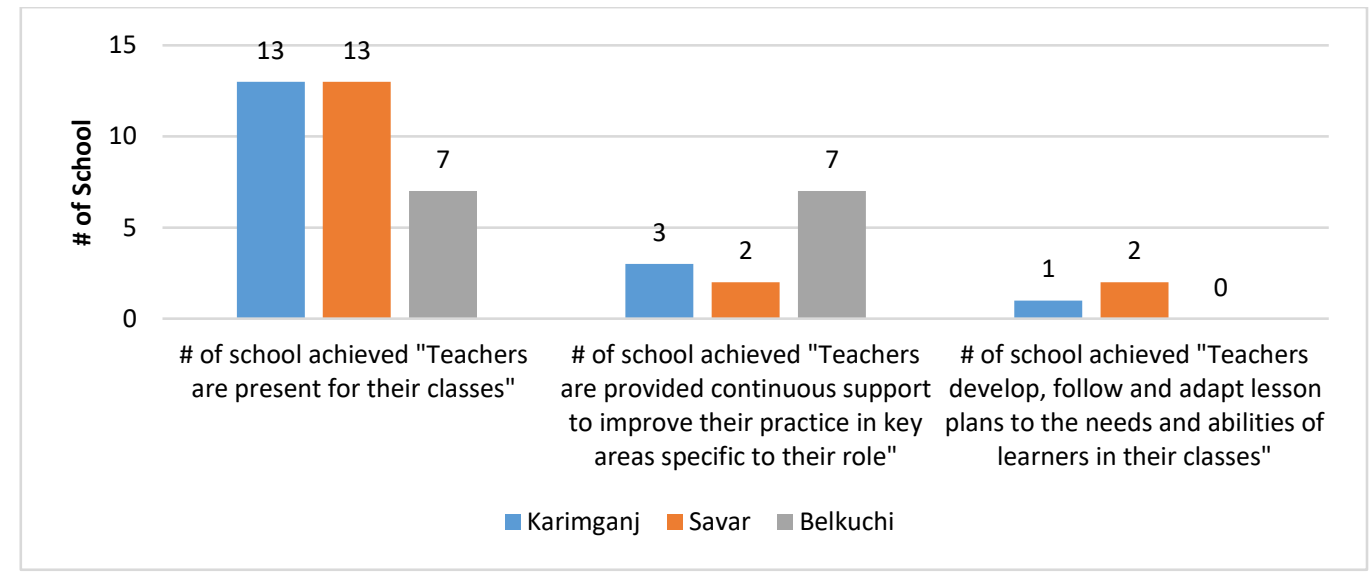

Figure 6: Teachers presence in classroom in an inclusive view.

However, observers found that despite not having lesson plans teachers were positive in engaging students in classroom activities. It has been observed that, most of the students were participating and actively engaged in classroom activities and teachers were found much positive about engaging students in activity based group work in some of the lessons. Assistant teachers echoed the same saying that, group work activity can engage all the students, even the ones who feel 
shy to converse with the teachers. Apart from group work, teachers also conduct sessions and assess the students using the lecture and the question-answer methods. Though teachers have accepted that it is not possible to measure the learning outcomes for all the students by using only the question-answer method, however, according to them, big classrooms and huge number of students forced them to do so. Teachers also accepted that, it is not possible to take proper care of the slow learners and weak performers at all the times.

\section{Teaching Materials}

It was found that, teachers use different methods of teaching and learning as well as various type of materials to make the lesson easy and interesting to the students. Teachers from all areas informed that they use real objects such as- clock, trees, leaves etc. in the lessons along with pictures, posters, charts prepared by them. In addition to ensure active participation of the students, question-answer session, peer work, group work are common ways that used by the teachers.

\section{Teaching-Learning Methodologies}

As a part of teaching learning process, the lesson plan is one of the most important components in the teaching-learning which assists a teacher to get impactful preparation for a lesson. Few government officials informed that, all the teachers are asked to share their lesson plans beforehand but, data revealed that, the majority of the teachers do not follow any lesson plan. Few teachers bring written lesson plans and conduct their session according to the plan while many other prepare their lesson without following the formal lesson plan structure.

It has been found that, in case of using mother tongue in the classroom only 3 schools of Savar $(\mu=2)$ and Karimganj Upazila $(\mu=1)$ achieved the indicator, whereas there is no data or that no concrete evidence of teachers using mother tongue in Belkuchi Upazila. On the other hand, all the 3 Upazilas somehow achieved the QLE indicator of "Teachers ask individual questions and interact with the learner" for 1 to 5 schools $(6 \%$ to $33 \%$ of 15 GPS ) while 2 to 5 schools (13\% to $33 \%$ of 15 GPS) of Karimganj and Savar Upazila respectively achieved the indicator of "Teachers use some form of informal or formal learning assessment either on an on-going basis or at specified times during the school year" while no schools in Belkuchi Upazila have achieved any results for this indicator (Figure 7).

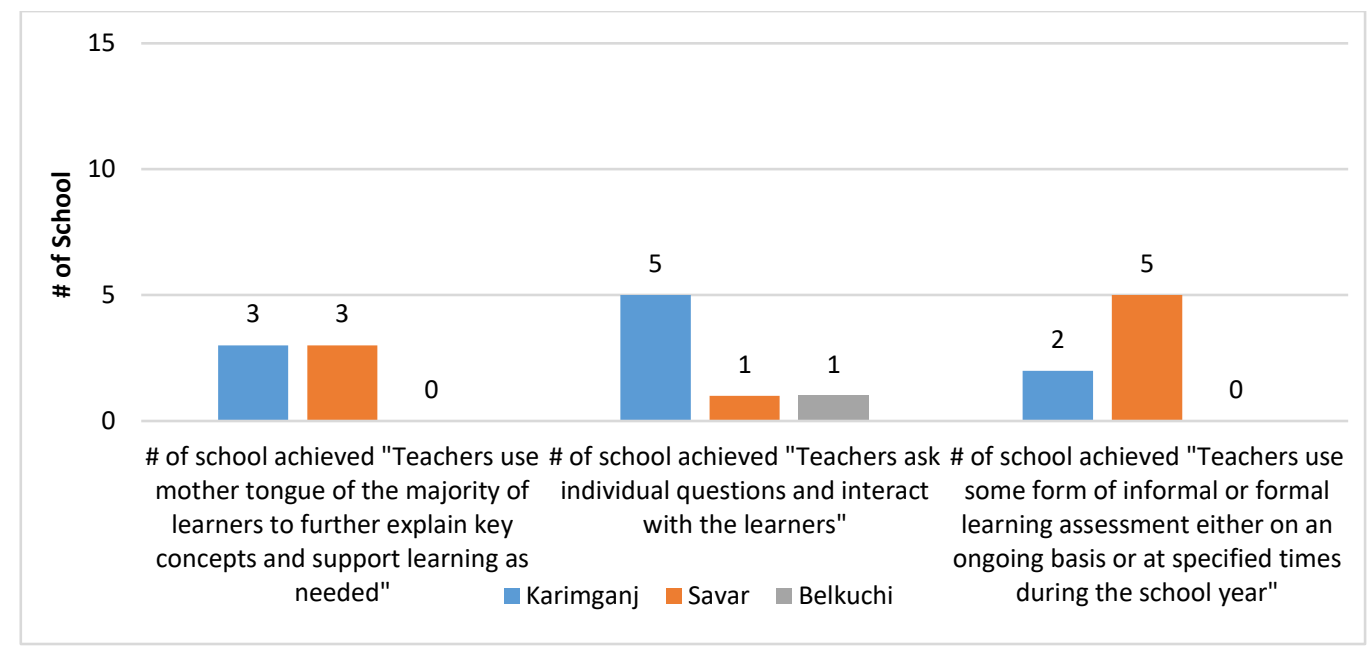

Figure 7: Teachers support to children in standard view.

It has been also analysed that, three to six schools of Karimganj and Savar Upazila have achieved results for all the indicators of deaf-mute children who can learn within a normal classroom, teachers interacting with all learners and also using different forms of learning assessment adapting to the needs of the children. Schools in Savar Upazila are comparatively doing better in case of teachers interacting well with all the learners. However, in great contrast it can be seen that no schools in Belkuchi Upazila has achieved any result in any of these indicators (Figure 8). 


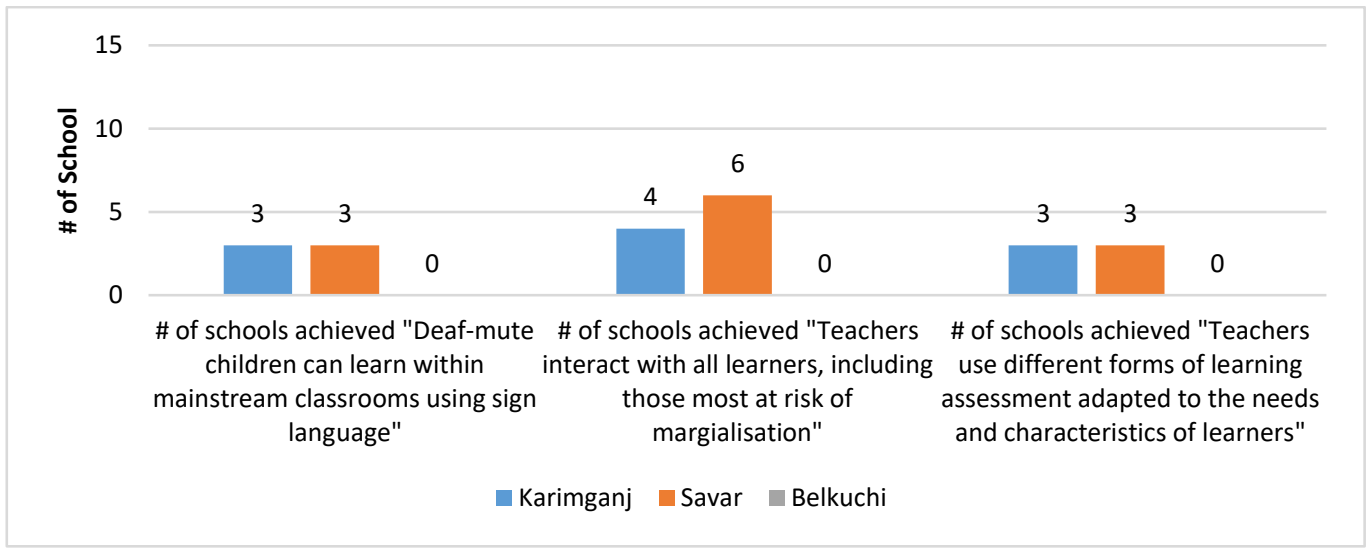

Figure 8: Teachers support to children in an inclusive view.

\section{Conclusion}

To ensure the inclusion of all children in schools, it is critical to comprehend schools' attitudes towards inclusive education. While the school authorities may have a positive approach towards establishing a quality learning environment, overall infrastructural and psycho-social environments are hampering an inclusive school environment. Most of the schools have safety issues, which is the first and foremost requirement which must be met before developing a quality learning environment. The need for a boundary wall around the school premises was rightly emphasized by most of the parents and teachers interviewed. Furthermore, in some schools, other than the teaching process, the overall environment is worsened by the practice of an unfriendly code of conduct and even the use of violence against the students by the teachers. The environment is detrimental for any meaningful participation and learning by children with disabilities.

In spite of the significant achievement in primary level enrolment in schools, still a big number of children are not in schools in the targeted areas. The enrolment status of children with disabilities are $48 \%$. In social and cultural activities, though children with disabilities who are in school get the opportunities to participate, but the participation of out of school children is very low pushing them further below the marginalization ladder. The number of children with disabilities decreased gradually in the upper classes. Teachers use different methods of teaching as well as various type of materials to make the lesson easy and interesting to the students. The lesson plan is one of the most important components in the teachinglearning which assists a teacher to get impactful preparation for a lesson. But the majority of the teachers do not follow any lesson plan. According to Nes (2000) the way in which teachers are trained in their initial education seems to have a serious role to play in the development of inclusive practices in the schools they will work at in future. In addition, Haug (2003) argues that if student teachers develop inclusive practices at university these will then be transferred later to their practice as teachers.

Despite the fact that this is a rather small sample sized assessment, it could be useful for higher education institutions and developmental organizations that try to design pre-service teachers training and professional development programmes. The authors would like to make the following points recommendations: -

Interventions need to take place for making school environment (pathway, toilet, classroom, drinking water facility, and playground) accessible and safe for all children, particularly those with disabilities.

Needs based budget should be allocated for the education section in local Government yearly budget plan as well a proinclusive fund utilization guideline is also required for proper utilization of the existing funds.

Comprehensive teachers training and capacity development interventions need to be made for teachers for making inclusive pedagogy a common practise.

Interventions have to consider providing technical support and guidelines to teachers for developing multi-sensory teaching/educational materials. 
Interventions need to focus on ensuring practice of pro-inclusive co-curricular activities at school level also finding practical ways to reach out to out of school children with disabilities.

Interventions have to be designed that would cover the inclusive leadership quality development training for Upazila Education Officers, Assistant Upazilla Education Officers, Upazilla Resource Centre instructors, Union Parishad Chairman.

Interventions should take place to develop a local level professional learning community of practise for solving challenges of implementation of inclusive education at local level.

\section{Acknowledgement}

We would like to thank Dr. Ishtiaq Manan, Deputy Country Director of Save the Children for his inspirational guidance and hands on support. Thanks are also due to Aklima Sharmin for giving her time generously during the peer review process and Rahul Kanti Barua for his contribution in data analysis part. Most importantly, we would like to convey our deepest gratitude to all the respondents, school's authorities, government officials and respective communities of Belkuchi, Karimganj and Savar Upazillas who provided invaluable inputs for the study.

\section{Notes on contributors}

Bushra Zulfiqar, is Sector Director for Education at Save the Children in Bangladesh.

Mohammed Kamal Hossain, is Project Director for an inclusive education project named Holistic approach towards Promotion of Inclusive Education (HOPE)at Save the Children in Bangladesh.

Md. Najmul Hossain, is working in HOPE Project as Manager-Community Based Rehabilitation \& Inclusive Education at Save the Children in Bangladesh.

Md. Shahinujjaman, is working in HOPE Project as Deputy Manager-Monitoring Evaluation Accountability and Learning at Save the Children in Bangladesh.

\section{Declaration of interest statement}

The authors declare that there is no conflict of interests regarding the publication of this paper.

\section{References}

[1] Ahuja A. \& Ibrahim M. D. (2006). An assessment of inclusive education in Bangladesh. Dhaka: UNESCO-Dhaka

[2] Ainscow, M. (2005) Developing inclusive education systems: what are the levers for change? Journal of Educational Change 6, 109-124.

[3] BBS (2011). Bangladesh Population and Housing Census 2011. Bangladesh Bureau of Statistics 2011.

[4] BBS and UNICEF (2014). Out of School Children in Bangladesh, Bangladesh Institute of Development Studies, Bangladesh Bureau of Statistics and UNICEF, December 2014.

[5] DPE (2015). Annual Sector Performance Report 2015, Department of Primary Education. Government of Bangladesh.

[6] Barnyak NC, Paquette KR (2010). An investigation of elementary pre-service teachers' reading instructional beliefs. Reading Improvement; 47(1): 7-17.

[7] CAMPE (2011). The status of un-served children in education Children with Disability in Bangladesh. Dhaka: Bangladesh.

[8] DPE (2002). CSID and Cambridge Consortium, 'Educating Children in Difficult Circumstances: Children with disability', ESTEEM II Study, Bangladesh Ministry of Primary and Mass Education, Directorate of Primary Education, 2002.

[9] DPE (2012). Bangladesh primary education annual sector performance report (ASPR-2012).

[10] Forlin, C., Loreman, T., Sharma, U., \& Earle, C. (2009). Demographic differences in changing pre-service teachers' attitudes, sentiments and concerns about inclusive education. International Journal of Inclusive Education, 13(2), 195-209.

[11] Haug, P. (2003) Qualifying teachers for the school for all, in: T. Booth, K. Nes \& M. Stromstad (Eds) Developing inclusive teacher education (London, Routledge/Falmer), 97-115.

[12] HIES (2016). Household Income and Expenditure Survey 2016. Bangladesh Bureau of Statistics 2016. 
[13] Jerlinder K, Danermark B, Gill P (2010). Swedish primary-school teachers' attitudes to inclusion- the case of PE and pupils with physical disabilities. European Journal of Special Needs Education; 25(1): 45-57.

[14] Kosko, K., \& Wilkins, J. (2009). General educators' in-service training and their self-perceived ability to adapt instruction for students with IEPs. The Professional Educator, 33(2), 1-10.

[15] Malak MS (2013). Inclusive education reform in Bangladesh: Pre-service teachers' responses to include students with SEN in regular classrooms. International Journal of Instruction; 6(1): 195-214.

[16] MOE (2010).The national education policy 2010. Dhaka: The Government of Bangladesh.

[17] Munir, S.Z., and Islam, M.R. (2005). Analysis and modification of the certificate in education curriculum of the primary training institute incorporating components of inclusive education. Dhaka: UNESCO.

[18] Nes, K. (2000) The inclusive school and teacher education: about curricula and cultures in initial teacher education. Paper presented at the Proceedings of the 5th International Special Education Conference, Manchester, UK, July 2000.

[19] Robert Scott Spence (2010). The effects of inclusion on the academic achievement of regular education students, A Dissertation Submitted to the Graduate Faculty of Georgia Southern University in Partial Fulfillment of the Requirements for the Degree Doctor of Education.

[20] Save the Children (2014). Save the children stands for Inclusive Education. https://onenet.savethechildren.net/whatwedo/education/Pages/Inclusive- ducation.aspx

[21] Sermier Dessemontet R, Bless G. (2013). The impact of including children with intellectual disability in general education classrooms on the academic achievement of their low-, average-, and high-achieving peers. Journal of Intellectual and Development Disability 38(1):23-30.

[22] UN (2008). Convention on Rights of Persons with Disabilities. Retrieved September 17, 2010, from http://www.un.org/esa/socdev/enable//documents/tccconve.pdf

[23] UNDP (2015). Goal 4: Quality Education, Retrieved June 15, 2016, from http://www.undp.org/content/undp/en/home/sdgoverview/post-2015development-agenda/goal-4.html

[24] UNESCO (2009). Inclusive education: The way of the future. Final Report of the International Conference of Education (48th Session). Paris: UNESCO.

[25] UNESCO. (1994). Salamanca statement and framework for action on special education needs. Paris: United Nations. 